\title{
CORRIGENDUM
}

\section{Corrigendum: The emerging biology of the nitrite anion}

Mark T Gladwin, Alan N Schechter, Daniel B Kim-Shapiro, Rakesh P Patel, Neil Hogg, Sruti Shiva, Richard O Cannon III, Malte Kelm, David A Wink, Michael Graham Espey, Edward H Oldfield, Ryszard M Pluta, Bruce A Freeman, Jack R Lancaster Jr, Martin Feelisch \& Jon O Lundberg

Nat. Chem. Biol. 1, 308-314 (2005)

Some information was omitted from Table 1 of this article. The table should have indicated that the first report of cells (macrophages) generating nitrite and nitrate was published in 1985 by Stuehr and Marletta (Stuehr, D.J. \& Marletta, M.A., Mammalian nitrate biosynthesis: mouse macrophages produce nitrite and nitrate in response to Escherichia coli lipopolysaccharide, Proc. Natl. Acad. Sci. USA 82, 7738-7742, 1985). 